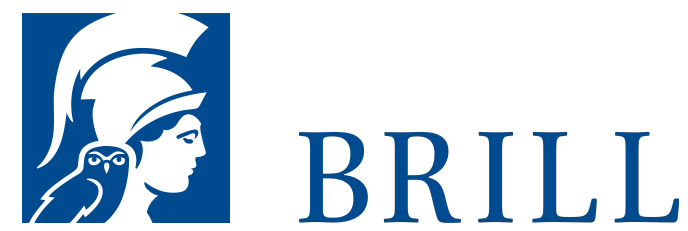

\title{
Veränderung in Zeichen
}

Studien zu einem semiotisch-pragmatischen

Veränderungsbegriff

Author: Matthias Warkus

Was heißt eigentlich, etwas habe sich verändert? Eine gängige Antwort lautet: Es heißt, dass ein Gegenstand zwischen zwei Zeitpunkten eine Eigenschaft verloren oder eine neue bekommen hat. Nun gerät man in größte Schwierigkeiten, wenn man ausschließlich mit diesen Mitteln (Gegenstände, Eigenschaften, Zeiten) die sich verändernde Welt plausibel und alltagstauglich beschreiben möchte. Es besteht daher unter den Philosophen, die einen Begriff von Veränderung als Eigenschaftswechsel akzeptieren, keinerlei Einigkeit über dessen genauen Entwurf. Dieses Buch macht den radikalen Gegenvorschlag, Veränderung als Verhältnis zwischen bedeutsamen Handlungen (d.h. Zeichen) zu beschreiben, ohne von Gegenständen, Eigenschaften und Zeiten zu reden. Als Grundlage dient dabei eine robuste, auf Praxistauglichkeit hin, aber ohne unzulässige Vereinfachung entwickelte Lesart der Zeichentheorie von C. S. Peirce. Dabei erweist sich ein solcher semiotisch-pragmatischer Veränderungsbegriff als schlüssig, anschlussfähig und nützlich. Veränderung als Eigenschaftswechsel stellt sich mit der richtigen Interpretation ihrer Voraussetzungen als Spezialfall des allgemeineren semiotisch- pragmatischen Begriffs heraus.

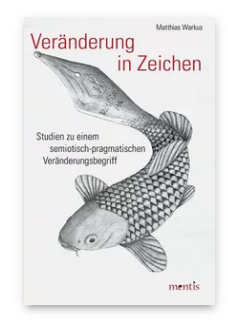

Pages: 277

Seiten

Language:

German

Subjects:

General,

Philosophy

Publisher: Brill | mentis

E-Book (PDF)

Released online: o8 Sep 2015

ISBN: 978-3-

95743-895-9

List price

Paperback

Publication date: o8 Sep 2015

ISBN: 978-3-

95743-016-8

List price 
For more information see brill.com

Order information: Order online at brill.com +44330 333 0049 | customerservices@brill.com Submission information: brill.com/authors

Titles published by Brill | Fink, Brill | mentis or Brill | Schöningh: +49(o)715413279216| brill@brocom.de 